\title{
Langenbeck's archives of surgery 2011: new concepts and design
}

\author{
T. Welsch • M. Schneider • M. W. Büchler
}

Published online: 1 December 2010

(C) Springer-Verlag 2010

Starting with the present issue of Langenbeck's Archives of Surgery, the journal comes with a new cover and Editorial Board. Under the former Editor-in-Chief Professor Beger, Langenbeck's Archives of Surgery has been established as an internationally accepted, competitive, Englishpublishing journal with increasing impact during the past 12 years.

The continuing aim of Langenbeck's Archives of Surgery is to publish top results within the field of clinical surgery and basic surgical research. This issue launches a new series of paired first-rate review articles on related clinical and scientific topics authored by leading international experts in their field. These reviews are selectively invited by the editor-in-chief, but regularly submitted outstanding reviews are also welcome and considered for this novel journal section. The present issue features two invited review articles on the subject of intestinal ischemia. Brigitte Vollmar and Michael D. Menger excellently illustrate the current knowledge of microcirculatory pathology and functional consequences [1]. The challenging clinical treatment concept of intestinal ischemia is outlined and updated by the group of Hans J. Schlitt [2]. Both reviews inspire clinical trials that focus on novel complex molecular pathogenic mechanisms in order to accomplish further progress in the management of intestinal ischemic and reperfusion injury.

Future types of manuscripts evaluated for publication in Langenbeck's Archives of Surgery will also include rapid communications reporting cutting-edge findings of high relevance. For those articles, the editorial board guarantees a distinct quick peer-review process.

Surgeons are welcome to submit pioneering surgical techniques and treatment concepts in the journal's "How-Ido-it"-section. A focus will be placed on data from controlled clinical trials and systematic reviews or meta-analysis.

We warmly thank all people that contributed to the updated content and design of Langenbeck's Archives of Surgery, and hope that the readers enjoy and benefit from the presented articles in the this issue.

\section{References}

1. Vollmar B and Menger MD (2010) Intestinal ischemia/reperfusion: microcirculatory pathology and functional consequences. Langenbecks Arch Surg 396 (1)

2. Renner P, Kienle K, Dahlke MH, Heiss P, Pfister K, Stroszczynski C, Piso P, Schlitt HJ (2010) Intestinal ischemia: current treatment concepts. Langenbecks Arch Surg 396 (1)

T. Welsch $\cdot$ M. Schneider $\cdot$ M. W. Büchler $(\bowtie)$ 